\title{
Star-spangled Shamisen: In search of the Jimi Hendrix of the... [insert instrument here]
}

\author{
Brent Keogh is a Lecturer in Communication at \\ UTS, and currently convenes Culture: Plugged and \\ Unplugged, Communications Practice Project and \\ Professional Internship. He completed his doctoral \\ studies at Macquarie University in 2014, examin- \\ ing the discourse of World Music in Australia.
}

\author{
University of Technology Sydney \\ 15 Broadway \\ Ultimo NSW 2007 \\ Sydney, Australia \\ brent.keogh@uts.edu.au
}

\begin{abstract}
A brief internet search of the phrase 'the Jimi Hendrix of...' followed by any instrument (for example, the bass guitar) reveals numerous examples of musicians promoting themselves, being marketed or being reviewed as the 'Jimi Hendrix' of that instrument. While some of the comparisons being made are arguably less tenuous—electric sitar, oud, mandolin—other instruments stretch the analogy. These include the 'Jimi Hendrix' of the bagpipe, clarinet, washboard, sampler and the jug. This phrase is not only applied to instrumentalists but sometimes takes on a national, racial or geographic dimension: such is the case with Mikhl Yosef Gusikow, described as the Jewish 'Jimi Hendrix', and Bombino, the 'Jimi Hendrix' of the Desert. This article critically examines the instances in which the phrase 'the Jimi Hendrix of the [insert instrument here]' is used to market and promote contemporary musicians. I explore some of the reasons why the rock guitarist Jimi Hendrix continues to be invoked as musicians position themselves in global markets, drawing attention to different aspects of the Jimi Hendrix myth that are appropriated by musicians and the various discourses around music practice. In order to do this, I employ Greenblatt's theory of social energy to critically frame such statements beyond the limits of political economy, as well as document contemporary cases of this phenomenon.
\end{abstract}

Keywords: discourse; Jimi Hendrix; music; music industry; music journalism; popular music; social energy

\section{Introduction}

'The Jimi Hendrix of the [insert instrument here]' is a phrase that frequently occurs in contemporary popular and world music discourse. A modest list of performers fitting this description can be quickly compiled, including violinist Eileen Ivers (Ivers n.d.), ukulele exponent Jake Shimabukuro (Dukes 2012), pipa exponent Lui Pui-Yuen (Kefner n.d.), ngoni exponent Bassekou Kouyate (Maan 2012), 
harpist Deborah Henson-Conant (Hip Harp n.d.), Bombino-'the Jimi Hendrix of the Desert' (This is Africa 2011), sitar exponent Dawoud (NiftyNYC 2012), washboard exponent Leo Thomas (CD Baby n.d.), banjoist Béla Fleck (JPlay n.d.), and a dedicated Facebook page to 'the Jimi Hendrix of the Spoons' (Jimi Hendrix of Spoons n.d.). The phrase can be attributed to musicians from a variety of disciplinary backgrounds and geographical locations who play a diverse array of musical instruments and are associated with the late guitarist and icon of 1960s counter-culture, Jimi Hendrix. Additionally, the phrase has particular relevance for musicians of non-Western musical backgrounds and disciplines, as they seek to connect to transnational markets. From this brief list above, one might question the links between Jimi Hendrix and the instruments specified; what has Jimi Hendrix got to do with playing the spoons? It is also legitimate to question the links between the artists themselves; what connections exist between the shamisen and the washboard? However, phrases such as 'the Jimi Hendrix of the [insert instrument here]' are not isolated to this musician. In fact, the practice of deferring to previously established artists (especially when 'breaking in' a new musician) has become common journalistic practice. Phrases such as 'If you love Joni Mitchell, you'll love Laura Marling' (Draper 2017) are the stock-in-trade of music journalists (McClain 2016: 1217), bloggers, promoters, and digital streaming services where this logic now extends to inform the algorithmic construction of personalized playlists such as Spotify's 'Discover Weekly'. And yet, the invocation of established artists is not simply the work of professional or amateur music journalists as they shape and compose the histories of popular music (Weisethaunet and Lindberg 2010: 467; Brennan 2013: 559). This discursive work is also undertaken by the musicians themselves as they jostle and position themselves in global markets. In this article, I unpack the use of canonical popular music figures as they are put to discursive use in the transnational music industries. I also highlight samples of Australian and international music journalism in order to demonstrate the wide-ranging ramifications of this discursive posturing as it plays out in local and global economies. Greenblatt's theoretical framework of 'social energy' (1988) is used here to extend the conversation beyond a limited reading of this phenomenon, whereby such statements are simply used to encourage consumption of popular cultural texts in a capitalist political economy (Scannell 2011). While still acknowledging the role such statements play in facilitating acts of consumption, I demonstrate that the phenomenon itself has historically existed outside of

1. 'The Daily Mix' is described on Spotify's website as 'Introducing the music that you love minus the effort ... Based on the different styles of music you regularly listen to, each mix is loaded with artists you love, plus a sprinkling of new discoveries that fit the vibe too'. Online at https:// support.spotify.com/us/using spotify/playlists/daily-mix/ (accessed 2 February 2018).

(C) Equinox Publishing Ltd 2018.

\section{evuinoxonline}


a capitalist mode of production, and thus a critical treatment of such statements requires a different theoretical framework to explain their value in diverse cultural and economic contexts. By applying Greenblatt's model, I discuss the ways in which such statements re-energize the 'cultural battery' of Jimi Hendrix, while in turn providing artists an opportunity to plug into the huge energy reserves of canonical artists.

\section{'Shall I compare thee to....?'}

The practice of deferring to established and/or canonical figures is standard practice in music journalism. Whether it is comparisons between Phish and the Grateful Dead (McCain 2016), Courtney Love and Bon Jovi (Davies 2001: 303), or Amy Winehouse and Sid Vicious (Berkers and Eeckelaer 2014:11), music criticism 'regularly explains the new through the old' (McCain 2016: 1217). This practice of deferral and comparison has drawn critical scrutiny, such that the practice has been considered in largely disparaging terms. Scannell has provided a potent critical examination of the uses of such statements with regards to the similar phrase 'the New Bob Dylan' (2011: 1-15). Statements such as 'the New Bob Dylan' have a very similar function and formulation to the 'Jimi Hendrix of the [insert instrument here]'. Scannell argues vis-à-vis a Deleuzian theoretical framework that this kind of statement is reflective of the self-perpetuating ideology of rock (2011: 1). His article helpfully critiques the use of clichés (such as 'the New Bob Dylan' or the 'Jimi Hendrix of the [insert instrument here]') as they serve the purposes of transnational capital. It also helpfully highlights a tendency to associate emerging artists with canonical figures of popular music, as large record companies and music journalists respond to the pressures of the digital age on the music industries (Scannell 2011: 1). The argument suggests that it is much easier to promote a new artist by comparison to a pre-existing canonical figure to speed up the process of the formation of a fan base, effectively transferring listeners and connecting the artist to new markets.

Scannell is not alone in connecting this form of journalistic 'framing' with the reductionistic practices of mass culture, as McCain explains that 'categorizing, classifying, and ordering are habitual functions of commodified mass media that aim to sell units and unscramble our world in 250-word articles' (2016: 1217). However, the argument in this article diverges and extends arguments that reduce the practice of deferral as though it were a phenomenon unique to mass culture and the tentacles of a capitalist mode of production. For example, in Scannell's critique of clichés such as 'the New Bob Dylan', he argues these statements form part of a homogenizing loop that traps creative thought in the service of capital (Scannell 2011: 8). The antidote to this malady can be achieved if

\section{eevinoxonline}


these subjects pursue a Deleuzian programme of creativity (that is, the pursuit of difference and the creation of affective language [Scannell 2011:4, 7, 12]), in order to be 'true' artists/writers/'people to come'. Putting to one side his arguments concerning music and language, ${ }^{2}$ I diverge from Scannell here; statements such as 'the New Bob Dylan' or the 'Jimi Hendrix of the [insert instrument here]' cannot simply be understood as part of the 'self-perpetuating ideology of rock', not least because similar statements have pre-existed and continue to operate outside of the discursive formations of rock as a genre. In Western art music traditions, for example, deferring to canonical figures to introduce musicians, often child prodigies, to new markets has been a staple practice for some time. For example, the phrase 'the New Mozart' has been in circulation at least since 1783, when Beethoven's teacher Gottlob Neefe wrote concerning his student in the Magazin der Muzik, 'He would surely become a second Wolfgang Amadeus Mozart, if he continued as he has begun' (Neefe cited in Cooper 2008: 9). Similarly, in 1845, the Bath Chronicle Gazette published a piece regarding then sixyear-old child prodigy John Sebastian Mills. The piece revels in the child's ability to play Bach, Handel and Vanhall from memory, and predicts that, "[s] uch precocious ability, if properly trained and developed, may lead to marvellous results. Perhaps-who can say-to a new Mozart' (Bath Chronicle and Weekly Gazette 1845: 4). In 1909, the West Gippsland Gazette featured a story introducing 'the latest child prodigy': then 11-year-old Hungarian George Szell, as the 'New Mozart' (De Chateleux 1909: 5).

Paganini is also commonly deferred to in order to introduce emerging musicians and even compare great musicians of the past. In 1916 the Étude Magazine published a piece where author Henry T. Fink ponders the question 'Was Liszt the Paganini of the Piano?' (Fink 1916). In 1920, the Queenslander ran a story on the London debut of then 20-year-old Russian violinist, Jascha Heifetz, calling him 'a new Paganini' (Queenslander 1920: 15). This article mentions that Heifetz had been based in America for the previous year, where he was 'compared to Paganini' (Queenslander 1920: 15). If we included in this discussion the practice of describ-

2. Scannell argues that 'music and writing have no inherent kinship. In the music writing process, the power of music is subsumed into a foreign modality; it is captured and rendered into the printed word, made to signify, made to represent something, no matter how far from reality this representation may be' (Scannell 2011:4). I disagree with this statement insofar as the connections between writing and music have been a feature of musical thought for a very long time (Levine 1984: 238). For example, playing the guqin (a Chinese zither instrument) was seen as intrinsically connected to calligraphy and sword play (Fang and Schiller 2002: 44-45). To say that there is no kinship between language (or writing) and music is to expose oneself to the implicit critique of sonic cultures that have formulated complex aesthetic and artistic practices, where these connections are not only articulated, but also essential to the pursuit of creative practice.

(c) Equinox Publishing ltd 2018.

\section{equinoxonline}


ing emerging musicians as 'successors to' previously established and celebrated musicians (for example, composer Antonio Vivaldi as the successor to Angelico Correlli), there is an extensive, and significant, history of 'breaking in' new artists with deference to established figures. Examples would abound if we were to consider this pattern of deferral in other genres of music-in jazz, French critics in the 1960s compared Theolonious Monk to Claude Debussy and Erik Satie (Perchard 2011: 65); similarly the Canberra Times published a piece during Dizzy Gillespie's Australian tour in 1988, calling fellow musician and trumpeter Jon Faddis, 'Gillespie's heir apparent'3 (Uhlmann 1988: 24). This deferral to established figures to introduce emerging artists, or as framing devices for pieces of music journalism, has evidently been a historically consistent practice across musical genres and modes of production. ${ }^{4}$ To argue that statements such as 'the New Bob Dylan' or the 'Jimi Hendrix of the [insert instrument here]' are somehow exclusive to, or symptomatic of, the 'self-perpetuating ideology of rock', is limited; this argument ignores how similar discursive moves are made outside of the Western pop/ rock canon, in diverse geographical spaces, at different moments and in diverse economic contexts.

Theoretically framing such statements as part of a (semi)totalizing 'loop' also fails to acknowledge that statements such as 'the New Bob Dylan' or the 'Jimi Hendrix of [insert instrument here]' can be thought of as a form of productive social energy. For Scannell, these statements are only characterized as negative clichés, unproductive energy that circulates ad infinitum in the transnational pursuit of capital. But this is not the only effect these statements produce-they can be thought of as a productive form of social energy; they are productive in that they inject new energy into 'texts' that circulate across time, genre, and diverse modes of production. While these clichés are admittedly reductive and essentialist, they are not reductive in a totalizing way; the cliché, as a discursive moment, is not the only discursive moment that is connected to that artist. For example, while oud player Joseph Tawadros may be referred to as the Jimi Hendrix of the oud in one discursive context, he is not always referred to in this way. He is also discursively identified as Egyptian, Australian, a classical artist, a jazz artist, a world music artist, a three-time ARIA award winner, and so on (Keogh 2015: 7). Despite

3. This article even discusses Faddis's reluctance to being nominated Gillespie's heir, and that this comparison actually drove him away from public performance for a time (Uhlmann 1988: 24).

4. 'The New Mozart' as it was applied to Beethoven in 1783 exemplifies this point. The statement was made at a time when the impacts of the Industrial Revolution were only just being felt in Austria, a country within an Empire still largely characterized by an agrarian mode of production (Hobsbawm 1996: 14, 23).

(C) Equinox Publishing ltd 2018.

\section{equinoxonline}


the frequent resort to clichés, the artist is always more complex than the reduction; they are already a complex assemblage of identities, objects, meanings, histories, languages, objects, subject positions, sounds, affects, intentions, and capital, that transcends the discursive short cut.

So while Scannell's arguments are certainly useful in identifying these statements/clichés as the invocation of canonical artists in the service of global capitalist imperatives, the critical framing of these statements tends to reduce the scope of their discursive work, and relies on a problematic series of binaries to diagnose these statements as symptoms of a capitalist malady. While it is true these statements are put to use to facilitate, perpetuate, and encourage musical consumption, the argument in this article is that they do more than just this work. It is this more that needs to be addressed with regards to statements such as 'the Jimi Hendrix of the [insert instrument here]'.

\section{Jimi Hendrix as a cultural 'battery'}

In order to address some of the limitations in the existing scholarship concerning this phenomenon of deferral, I argue that Stephen Greenblatt's theory of social energy provides a useful framework for critically discussing these statements, and for addressing the positive energy that these statements can generate, as he sought to observe the ways in which 'cultural objects acquire[d] compelling force' (1988: 5). Greenblatt's study concerns the ways Shakespearean texts acquired social energy in Renaissance England; however, his theories are applicable to the ways in which cultural objects circulate and acquire social energy more generally. Greenblatt employs the Greek word 'energia' to describe social energy as opposed to a scientific understanding of the term (1988: 6). He applies this concept to certain works of art, which continue to generate 'the illusion of life', long after the perceived original moments of creative activity (1988: 7). Greenblatt is particularly interested in the process of movement connected to certain works of art, and the ways in which those works of art are re-energized and 'charged' by this movement (1988: 14). Writing about Shakespearean plays, he explains:

\footnotetext{
Plays are made up of multiple exchanges, and the exchanges are multiplied over time, since to the transactions through which the work first acquired social energy are added supplementary transactions through which the work renews its power in changed circumstances (Greenblatt 1988: 20).
}

Like Elizabethan plays, the phrase 'the Jimi Hendrix of the [insert instrument here]' can be discussed in terms of social energy. If Greenblatt's discussion of Elizabethan plays were applied to contemporary popular music, the text of 'Jimi Hendrix' is like a rechargeable battery, that gets re-powered every time it is transacted 
and exchanged, both temporally and spatially. Greenblatt's language regarding the social energy of Shakespeare is almost directly transferrable to the subject of Hendrix. Consider the following passage:

What then is the social energy that is being circulated? Power, charisma, sexual excitement, collective dreams, wonder, desire, anxiety, religious awe, freefloating intensities of experience: in a sense the question is absurd, for everything produced by the society can circulate unless it is deliberately excluded from circulation (Greenblatt 1988: 19).

While Jimi Hendrix the artist has passed away and the possibility for him to continue the act of creation is no more, ${ }^{5}$ it is the power, charisma, sexual excitement, dreams, desires, spirituality and intensities of experience associated with this musician that continue to circulate and acquire social energy through a myriad of exchanges and transactions in the transnational music industries. It is this circulation of energia that is essential to the very existence of musical canons. Musical canons are predicated on the social energy surrounding certain works and artists, and the movements, exchanges and transmissions that re-charge those works and artists so that they acquire the status of 'immortal', or 'great'. Without these transmissions, without the injection of social energy into works and artists, these acts of creativity would go the way of most creative acts, as Greenblatt states, 'dead on arrival' (1988: 7). Instead, what we see in the circulation of 'Jimi Hendrix' is the way in which social energy continues to generate the 'illusion of life' (ibid.).

Greenblatt theorized a preliminary list of 'modes of exchange' in which cultural objects acquire energy, specifically as it relates to the theatre (1988: 10-12). For the purposes of this discussion on music, I have adapted Greenblatt's original formulation of modes of exchange in order to more specifically treat the discursive invocation of Jimi Hendrix. These modes of exchange are not to be taken as exhaustive, but rather indicative of the kinds of transactions that characterize contemporary popular music and the acquisition of social energy:

1. Direct exchange: ephemeral, direct exchange e.g. live performance. This includes how the experience is remembered by those present at the event (fellow musicians, audience members, industry-lighting, managers, stage managers, sound engineers, record company representatives, etc.).

5. The recent phenomenon of the 'posthumous duet' does raise provocative questions about the possibility of artists, willingly or unwillingly, to continue to 'create' beyond the grave (Brunt 2015). For the purposes of this article, however, I draw a clear distinction between the active creative choices that a musician makes during their lifetime, as opposed to the possibility of further creative acts afforded by acts of schizophonia and schismogenesis (Feld 1994: 107), such as recordings, virtual reality (VR), and interactions with holographic projections of the artist in question.

(c) Equinox Publishing Ltd 2018.

\section{equinoxonline}


2. Indirect exchange: a musical act is reified, objectified, by the processes of schizophonia (Feld 1994: 103). In this sense, recording is like writing, in that the recording allows the musical work to become 'iterable' (Derrida 1977: 185-86)-recording affords the possibility of movement and repetition outside of those direct exchanges. As Feld comments, recording affords sound the possibility of new social life as sounds are split from their sources (schizophonia) and their origins (schismogenesis) (1994: 107). Indirect exchanges allow other modes of exchange that would not be possible if the music did not become iterable.

3. Appropriation: where the object appears to be in the public domain, adiaphora is the appropriation of 'things indifferent' (Greenblatt 1988: 9). The cultural artefact (i.e. Hendrix) can be appropriated directly by a musician, or it can be conferred-this is where the social energy of Jimi Hendrix is conferred onto an artist by another discursive authority (e.g. a record company executive, marketing director, agent, journalist, PR company, and so on).

4. Purchase: the social energy of Jimi Hendrix is re-charged through consumption. These include, but not exclusively, CD, vinyl and digital sales of Hendrix's music, digital streaming, t-shirts and clothing, books, magazines, posters, artwork, especially guitar related products-guitars (especially Fender Stratocasters), guitar straps, picks, DVD and book tutorials, effects pedals, pick ups, and so forth. It would also include the digital life of Hendrix as images circulate on numerous social media sites.

Using Greenblatt's formulation of social energy and acknowledging the ways in which musical texts acquire this energy through a series of complex transactions, it is possible to view both the construction of canons and the appropriation of its power as reliant on the dynamics of social energy. The circularity of canon formation that Kassabian describes for example, whereby new works and artists are accepted based on the aesthetic criteria of previously canonical figures (2010: 75), which in turn reinforces the established canon, could be considered as regular injections of social energy. This energy is not limitless, or self-perpetuating, for it requires the constant injection of social energy; however this inherent limitation does not undermine the power of canons and corporate stakeholders to reestablish and even increase their cultural and economic interests. Von Appen and Doehring's (2006: 28) discussion of the influence of the culture industries on the canonical status of The Beatles is a case in point, and could be seen as the culture industries re-energizing these artists and their artistic output. Consider the following passage: 
Specific strategies of the media and the record companies keep certain musicians and bands present in the participants' minds ... [The Beatles] compilation 1 was a world-wide best seller; Yellow Submarine (1999) and Let it Be (2003) have been re-released in digitally mastered versions; George Harrison's death, both McCartney's and Lennon's sixtieth birthdays, as well as the twentieth anniversary of the latter's death, led to coverage on TV, radio, and in the press and certainly resulted in much media presentation of Beatles music; The Beatles' Anthology, encompassing TV broadcasts, three double-CDs, a book, a videoand DVD-edition, provided 'new' material for fans around the world for several years ... By integrating these influences into our perspective, we can explain why The Beatles are more present in the canon than Buddy Holly for example (von Appen and Doehring 2006: 28).

Following Greenblatt's theory on social energy, it was not that fans were provided with 'new Beatles material' to consume; rather 'The Beatles'-as artists and especially as commodities-were injected with new social energy via these modes of exchange that subsequently contributes to their canonical status. This then allows 'The Beatles' to be appropriated by the next band that comes along as the 'new Beatles' (bands like Oasis and One Direction come to mind here), which provides 'The Beatles' as cultural objects with even more social energy. One of the reasons Buddy Holly does not have as much of a presence in a particular version of the canon is because 'Buddy Holly' has not been re-charged to the same degree as The Beatles.

This theoretical framework is more flexible than analysing these statements purely within the logic of capitalist production, as the theoretical model can be applied to any mode of production or patronage system in which a cultural text (or texts) is produced. While it is possible to analyse a statement such as 'the J.S. Bach of the [insert instrument here]' or 'the New Mozart', as part of the capitalist imperative to encourage the consumption of its latest pseudo-individualized commodity (Adorno 2006: 78), the energy surrounding the cultural artefact of J.S. Bach or Vivaldi transgresses the historical advent of the capitalist organization of the economy. To understand why canonical figures like J.S. Bach are invoked in the present needs a critical analysis of the energy traces in different historical systems of musical patronage. Therefore, in applying Greenblatt's theoretical framework to statements such as 'the Jimi Hendrix of the [insert instrument here]', it is possible to consider these statements not simply as part of the self-perpetuating, capitalist ideology of rock, but as a productive expression of social energy that transgresses historical and spatialized modes of production. This social energy constructs canons, provides new artists with a means to appropriate the energy of a predecessor, and injects that cultural object with renewed vitality.

\section{eevinoxonline}




\section{Plugging into 'Jimi Hendrix'}

While the statement 'the Jimi Hendrix of the [insert instrument here]' can be seen as part of a productive expression of social energy, these expressions are not homogeneous in their application. There is a diversity of significations and purposes associated with its use. Four discursive frames will be highlighted here, in which musicians plug into the energy of Hendrix. The first is plugging in through musical similitude; second, through dedication; thirdly, through the trope of the musical pioneer; and lastly, through claims of hybridity. It should be noted that musicians/journalists will often employ a number of these discursive moves in discussing the musician's music, and there is often much overlap between these discursive moves and the comparisons made between a musician and Hendrix.

\section{Musical Similitude}

One of the primary ways in which musicians plug into the social energy of Hendrix is through musical similitude, where their phrasing or 'sound' is likened to Hendrix's playing or the timbral qualities of his 'sound'. An example of this is Malian kora player Sékou Kouyaté, who has been dubbed the 'Jimi Hendrix of the African kora' on the City of Johannesburg webpage. Kouyaté has been compared to Hendrix in terms of his phrasing on the kora, and is said to have "earned himself the nickname "Jimi Hendrix Africain" because his vibrant renditions on the kora resemble Hendrix's famous guitar riffs' (Joburg 2008). The case of Kouyaté does appear to demonstrate the transference of social energy through adiaphora, the appropriation of 'things indifferent' (Greenblatt 1988: 9), whereby he plugs into the social energy through the perception of sonic semblance.

The 'Jimi Hendrix of [insert instrument here]' is also applied to virtuosic performers of a given instrument. In this sense, the musical similitude is not so much in a comparison of the tone of the instrument or the phrasing, but rather a gesture towards the shared virtuosic playing between the musician and Hendrix. This is the case with lvo Papasov, who has been called the 'Jimi Hendrix of the Clarinet'. A description of Papasov published on Virtual Womex provides some insight into why this musician is associated with Hendrix:

Papasov's playing is filled with wild runs, forceful shrieks, and elaborate melodic fantasies. To say that Papasov plays clarinet is as inadequate as saying 'Jimi Hendrix played electric guitar'. The first time I heard the group, I recognized the music immediately it was the folk music Frank Zappa only dreamed of [sic] (Phillips n.d.).

In this case, the connection drawn between Papasov and Hendrix is the recognition of the virtuosity and accomplishment that both musicians have on their 
respective instruments. Here the writer draws connections between the energy of Hendrix and Papasov's music-the choice of adjectives such as 'wild', 'forceful shrieks' suggests the musicians have tapped into a similar 'other worldly' muse. Interestingly, Papasov does not appear to have done collaborations with overtly popular music styles (such as blues, jazz, electro), and yet, this statement has still been applied to this musician.

\title{
Dedication
}

Another means by which artists plug into the social energy of Hendrix is through dedicating a work, project, or piece, to Hendrix. In addition to his phrasing and sound, Kouyaté has also plugged into the energy of Hendrix through dedication. Kouyatés album Electric Griot Land does this to some extent through titular reference. Another artist who has done this is South Indian guitarist Prasanna on his album Electric Ganesha Land, released in 2006. This album is a more overt dedication to Hendrix, as Prasanna states in the liner notes:

I see 'Electric Ganesha Land' as the journey of the modern rock guitar through the ancient temple towns of South India with the sounds of Carnatic music wafting through the air ... India may be the land of Sitar for many, but Jimi Hendrix would have found a home there too! I want to dedicate this to Jimi (Guitar Prasanna n.d.).

Track 10 on the album, titled 'Sri Jimi', is a good example of this musical dedication. A review of this album on All About Jazz.com commented on this track:

\begin{abstract}
Sri Jimi shows that it is more than just word play. Set in the auspicious Sri raga, it leaves the listener in no doubt about its musical antecedents. If you ever imagined the kind of music Jimi Hendrix might have played were he to be born in India in some other lifetime, you can bet your last dollar Sri Jimi would have his name on the credits. Wailing and whispering and meowing and ejaculating and singing, this is Sri raga like it is and never is. Like a large river assimilating the essence of the various streams merging in it, Sri Jimi is a true testament to Prasanna's Catholicism of musical imagination and influence (Vallikanth 2006).
\end{abstract}

Here the dedication to Hendrix is explicit. The dedication is both musical and sociocultural: the instrument is described in vivid anthropomorphic terms, expressing the extremes of human emotion, feeling and sexuality, that takes a traditional raga and injects new social energy into it with Hendrix as the muse.

\section{Musical pioneer and hybridity}

Musicians can also plug into Hendrix by claiming the status of the musical 'pioneer'. I have coupled these two frames together, as claims to hybridity are often a marker of the musicians' pioneering efforts. To provide evidence of their 'pio- 
neer' status, musicians often take 'traditional' music and fuse it with some form of contemporary popular music. Carlos Núñez is one such musician, who has been dubbed by Billboard magazine in 1997 as 'the Jimi Hendrix of the Bagpipes' (Wolf 2014). Núñez's innovation is inextricably tied to the discourses of hybridity and the perceptions of intercultural fusion. In an article published by Colorado Public Radio on the upcoming Colorado Scottish Festival, Wolf writes of Núñez: 'Fusing bagpipe music from different cultures together-such as from Galicia and Latin America-is how Núñez modernizes the typically traditional sounds' (Wolf 2014). The article is rich in discursive imagery, invoking intercultural hybridity. It mentions the hybrid origins of the instrument, the diverse national backgrounds of the Núñez band, and also featured a link to Núñez's 'rock-infused' arrangement of the traditional Celtic tune 'Raggle Taggle Gypsy'. The article also quotes the festival director, John Thornton, stating that he invited Núñez to perform at the festival due to the musician's 'cross-cultural appeal' (Wolf 2014). Núñez's projection of hybridity as innovation, and the consistent invocation of Hendrix, are summed up in this article when he states: 'the pipes are the electric guitar of Celtic music' (Wolf 2014).

Similarly, Mehdi Haddab has been dubbed 'the Jimi Hendrix of the oud', largely due to the discourse of hybridity concerning his music. Mehdi Haddab plays an electric oud through various amplifiers and effects. He is in many ways emblematic of the discourses or 'dogma' of hybridization (Aubert 2007: 55) that are characteristic of world and popular music, whereby musicians must submit themselves to the 'intercultural dictate' within the domain of contemporary popular music (Aubert 2007: 53-55). However, hybridity is not the only characteristic that is used to make connections with Hendrix. Haddab invokes Hendrix through discourses of virtuosity, musical similitude, as well as a sense of being a musical pioneer through cultural and technological hybridity-the oud is not typically played at high volumes, amplified, or played with guitar effects. World Music Central introduces Haddab's album Kalashnik Love in the following way:

\footnotetext{
'Kalashnik Love' ... combines tradition and future, ancient and urban, beauty and fury to stungunning effect. Laden with special guests and throbbing with raw rock energy it references everyone from The Cure and The Chemical Brothers to Algerian rai and other Arabic influences ... Electrified, amplified, and fuelled by creative fire, the Paris-based quartet charge towards a psychedelic horizon; slaloming through rock, dance, electro, hip-hop, world and other music-blazing a trail with raised fists, a hand brake turn, and a sharp spray of desert sand (World Music Central 2009).
}

In this instance, it is the 'rock energy' fused with Algerian rai and 'other Arabic influences' that create a convincing comparison to Hendrix. In this example, the process and expression of fusion and assimilation are venerated as though the musician 
were tapping into the same dionysian muse that Hendrix had courted some forty years earlier. This is evidenced further on in the article where extra-musical comparisons are made between Haddab and Hendrix. Haddab's performance style is compared to that of Hendrix as the author writes: 'audiences marvelled at Haddab's flamboyant, frenetic style (not for nothing has he been called the 'Hendrix of the oud')' (World Music Central 2009). Haddab also speaks frankly about a 'rage' that he feels he needs to express, a rage against 'Injustice. Inequality. The system', which is channelled through the performance of 'loud music' gravitating 'towards a psychedelic horizon' (ibid.). One could argue that there is a shared sense of orientalist (Said 1978) fascination between the two musicians, both non-white, both framed in classic orientalist binaries of exotic, untrammelled, mysterious, and other, conforming very much so to discursive practices that have existed at least since the world fairs of the nineteenth century, a discourse that Armstrong refers to as the 'subliming of the exotic' (Armstrong 1993: 199). Haddab is therefore an intriguing case study as he is discursively positioned in such a way as to conjure multiple aspects of the Hendrix myth: these include the musical pioneer; the creative genius; the racial other; and the pursuer of new timbres, tones and importantly volume. He is a figure who is also ideologically evocative of the psychedelic Hendrix, whose social energy as a 1960s counter-culture icon retains much of its potency.

\section{In search of a female 'Jimi Hendrix of the [insert instrument here]'}

The majority of the musicians discussed thus far have been male. However, female musicians are also referred to as 'the Jimi Hendrix of [insert instrument here]', though with less frequency. It should be noted that there are different implications for female artists compared to Hendrix, as opposed to male artists. As has been noted consistently in scholarship on music journalism, comparing a female artist to an established male artist often has the effect of legitimizing or authenticating the artist according to phallocentric values and entrenched 'sexist discourses' (see Davies 2001: 316; Berkers and Eeckalaer 2014). The cases of female artists compared to Jimi Hendrix affirm the authenticating effects of this journalistic frame. For example, Eileen lvers was dubbed the 'Jimi Hendrix of the violin' by Neil Strauss of the New York Times (Ivers n.d.). Ivers has been compared to Hendrix due to her explorations of diverse styles, through virtuosity and through musical similitude. Neil Strauss is credited as saying that lvers made her instrument 'sound like Hendrix's guitar' (Ivers n.d.). Similarly, Deborah Henson-Conant has been called the 'Jimi Hendrix of the harp' (Indiana University of Pennsylvania n.d.). She was given this title by guitar virtuoso Steve Vai-the irony of being compared to a canonical

(C) Equinox Publishing ltd 2018.

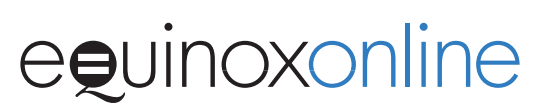


male artist by a canonical male artist is not lost here, and supports the critiques of the music industries more broadly as persistently patriarchal (see Strong 2011; Schmutz Faupel 2010). Like Mehdi Haddab, she plays an electrified version of her instrument and makes extensive use of loop pedals, and so fits into the narrative of a musical pioneer, both in terms of a hybrid approach, but also in the use of high volume and the incorporation of new technologies. Henson-Conant is also compared to Hendrix in terms of her performance style. In this respect, Hendrix is not the only person (or male) that she has been compared to-she has also been compared to Leonard Bernstein and Elvis Presley (Indiana University of Pennsylvania n.d.). A full exploration of these comparisons is beyond the scope of this study; however, it is notable that female performers are compared to canonical male figures such as Bernstein, Presley and Hendrix.

In addition to these musicians, there are a number of female guitarists who have plugged into the social energy of Hendrix. One example of this is Malina Moye, who has been called the 'female Hendrix'. An article posted on the website GuitarWorld.com described Moye in the following way:

Malina Moye is being touted as the female Jimi Hendrix, and it's no mystery why. Since 2004, Moye has been wowing audiences with her unique blend of rock ' $n$ ' roll, blues and soul. Like Hendrix, the left-handed Moye plays her Fender Strat upside down, and she channels her idol with screaming classic rock solos and blues riffs. She does a searing rendition of 'Foxy Lady'-renamed 'Sexxy Man'-and her song 'Alone' landed at No. 11 on the Billboard R\&B Hip Hop charts and No. 27 on the Hot 100. She was invited to play the National Anthem at a Vikings vs. Cowboys NFL game last year and was featured in the British documentary Stratmaster: The Greatest Guitar Story Ever Told (Whitmore and Blumenthal 2011).

In the case of Moye, the comparisons to Hendrix are explicit, to the extent that she is almost a mimic of the iconic guitarist, albeit female-from the choice of a Fender Stratocaster, played left-handed and upside-down, to the style/genre of music, and covers of Hendrix tunes. The comparison here is overt to the point of cliché: she even performed the American national anthem at an NFL game (Hendrix famously performed 'Star-Spangled Banner' at the first Woodstock festival).

\section{Discussion}

In view of these exceptions to the normative use of the phrase 'the Jimi Hendrix of [insert instrument here]', it is possible for women to both evoke and be accorded with this phrase, though there is a much higher representation of men associated with it. This observation adds weight to the significant amount of scholarship concerning the under-representation of women, especially as canonical figures in popular music (see for example Strong 2011; Schmutz Faupel 2010), though

(c) Equinox Publishing ltd 2018.

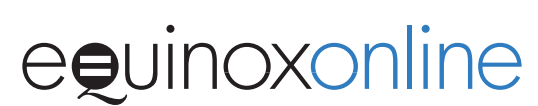


of course there are other female canonical figures to whom musicians are frequently compared, notably Joni Mitchell and Janis Joplin. Women who are identified as the 'Jimi Hendrix of [insert instrument here]' tend to be identified as such due to their performing traditionally 'active' or 'male' characteristics (Moi 1998: 104). That music journalism (and the artists' own descriptions of themselves) perpetuates discourses that authenticate the feminine through established and tired phallocentric discursive practices (for example, musical virtuosity and innovation) is not surprising (Davies 2001). It is possible that men are more associated with 'the Jimi Hendrix of' for a number of reasons. The most obvious reason may be due to the shared sex and gender identities of Hendrix and other male musicians. On a more subtle level though, it may be due to a greater proclivity to perform a certain kind of hyper-masculinity (Clay 2011: 9) that suits the myth and performance style of Hendrix. Sékou Kouyaté is a good example of this, when performing with the kora standing up; the phallic placement of the kora combined with sexual gyrations evoke images of Hendrix in his most celebrated hyper-masculine moments. That being said, Moye's performance style similarly invokes these hyper-masculine qualities. This discussion of 'the Jimi Hendrix of [insert instrument here]' and gender is thus extremely complex, and there is a danger here of reducing the complexities of the evidence into neat essentialisms. While it is possible to make some general points and speculations here, more work needs to be done to further reflect on the implications of "the Jimi Hendrix of [insert instrument here]' for female agency and the patriarchal values of the music industries more broadly.

These examples demonstrate a number of ways in which 'Jimi Hendrix' is discursively used by musicians, and the exchange of social energy that occurs when these transactions take place. Evidently, there is much overlap in the ways musicians plug into the cultural artefact of Hendrix. Other elements that are often referenced include a tendency towards mastery over the instrument, performance style, stage presence, and a certain kind of unorthodoxy. While this is by no means an exhaustive list of the ways musicians plug into Hendrix, or the number of musicians who do so, it gives some indication of the ways in which this is being done, both sonically and discursively. In particular, it provides an insight into how musicians who are typically located on the musical peripheries can acquire lucrative forms of patronage, build fan bases, international recognition, sell their music and so forth, by discursively plugging into 'the Jimi Hendrix of [insert instrument here]'.

\section{Conclusion}

Greenblatt's theory of social energy is a useful model for critically interrogating the complexities of statements such as 'the Jimi Hendrix of [insert instrument here]'.

(C) Equinox Publishing ltd 2018.

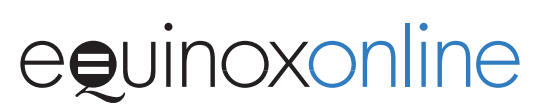


It is helpful for understanding how artists pragmatically position themselves within global industries and for identifying how certain cultural texts acquire energia through movement-those modes of exchange including direct exchange, indirect exchange, appropriation and commodification. Greenblatt's theory is also beneficial for identifying ways in which musicians from the perceived peripheries of power plug-into and take advantage of the immense cultural and material energy of the transnational music industries. Four types of deferral have been described here-musical similitude, dedication, musical pioneer, and hybriditythough, of course, there are many other ways artists can plug-in to this energy. Rather than simply dismiss such statements as part of the self-perpetuating ideology of rock, we can understand these statements as also contributing to the productive energy of cultural texts that are part of a much larger historical trend. These statements connect histories, articulate the present, and project into future music practices. Additionally, every time an artist plugs into 'Jimi Hendrix', the cultural object of Hendrix is re-charged and acquires more compelling force. Though these artists use Hendrix to further their career objectives, the cultural object of Hendrix requires these kinds of movements if it is to continue at all, and is thus dependent on these exchanges. While 'plugging into' Hendrix may provide the illusion of the 'self-perpetuating ideology of rock' (Scannell 2011: 1), no cultural object possesses self-sustaining energy. It is not because Jimi Hendrix is essentially more 'authentic', or the music more 'real' that he continues to be invoked in the present. Jimi Hendrix as a cultural object requires movement: it is dependent on the constant injection of social energy if it is to continue to sustain the 'illusion of life' (Greenblatt 1988: 7).

\section{References}

Adorno, T. W. 2006 [1941]. 'On Popular Music'. In Cultural Theory and Popular Culture Reader, 3rd edn, ed. John Storey, 73-84. Essex: Pearson Education.

Armstrong, Meg. 1993. '“A Jumble of Foreignness": The Sublime Musayums of NineteenthCentury Fairs and Expositions'. Cultural Critique 23: 199-250.

Aubert, Laurent. 2007. The Music of the Other: New Challenges for Ethnomusicology in a Global Age. Translated by Carlo Ribeiro. Hampshire: Ashgate.

Bath Chronicle and Weekly Gazette. 1845. 'Newmarket, First Spring Meeting'. 8 May: 4.

Berkers, Pauwke, and Merel Eeckelaer. 2014. 'Rock and Roll or Rock and Fall? Gendered Framing of the Rock and Roll Lifestyles of Amy Winehouse and Pete Doherty in British Broadsheets'. Journal of Gender Studies 23/1: 3-17. https://doi.org/10.1080/ 09589236.2012 .754347

Brennan, Matt. 2013. “"Nobody Likes Rock and Roll but the Public": Down Beat, Genre Boundaries and the Dismissal of Rock and Roll by Jazz Critics'. Popular Music and Society 36/5: 559-77. https://doi.org/10.1080/03007766.2012.718486

Brunt, Shelley. 2015. 'Performing Beyond the Grave: The Posthumous Duet'. In Death and the 
Rock Star, ed. Catherine Strong and Barbara Lebrun, 165-76. London: Ashgate/ Routledge.

CD Baby. n.d. 'New Awlins by Washboard Leo Thomas'. Online at http://www.cdbaby.com/ cd/washboardlt (accessed 7 January 2016).

Clay, A. 2011. 'Working Day and Night: Black Masculinity and the King of Pop'. Journal of Popular Music Studies 23/1: 3-18. https://doi.org/10.1111/j.1533-1598.2010.012 $61 . \mathrm{x}$

Cooper, B. 2008. Beethoven. Oxford and New York: Oxford University Press.

Davies, Helen. 2001. 'All Rock and Roll is Homosocial: The Representation of Women in the British Rock Music Press'. Popular Music 20/3: 301-319. https://doi.org/10.1017/ S0261143001001519

De Chateleux, R. 1909. West Gippsland Gazette (Warragul, Vic.: 1898-1930), Tuesday 9 February 1909: 5 .

Derrida, J. 1977. 'Signature, Event, Context'. Glyph 1:172-97.

Draper, 2017. 'If You Like Joni Mitchell... You'll Love Laura Marling'. Online at https://www. udiscovermusic.com/stories/if-you-like-joni-mitchell-youll-love-laura-marling/ (accessed 22 January 2018).

Dukes, B. 2012. "Jake Shimabukuro, the "Jimi Hendrix of the Ukulele", Releases Album Produced by Alan Parsons'. Online at http://ultimateclassicrock.com/jake-shimabukurothe-jimi-hendrix-of-the-ukulele/ (accessed 7 January 2016).

Fang, Zhao-hui, and David R. Schiller. 2002. 'A Critical Reflection on the Systematics of Traditional Chinese Learning'. Philosophy East and West 52/1: 36-49.

Feld, Steven. 1994. 'From Schizophonia to Schismogenesis: on the Discourses and Practices of "World Music" and "World Beat"'. In The Traffic in Culture: Refiguring Art and Anthropology, ed. George E. Marcus and Fred R. Myers, 96-126. Berkeley and Los Angeles: University of California Press.

Fink, H. 1916. 'Was Liszt the Paganini of the Piano?' Étude Magazine, Philadelphia, August 1916.

Guitar Prasanna. n.d. 'Electric Ganesha Land'. Online at http://www.guitarprasanna.com/ EGL/ (accessed 7 January 2016).

Greenblatt, S. 1988. 'Shakespearean Negotiations: The Circulation of Social Energy in Renaissance England'. In The New Historicism: Studies in Cultural Poetics, ed. Stephen Greenblatt, 1-20. California: University of California Press.

Hip Harp. n.d. 'Deborah Henson-Conant-About'. Online at http://www.hipharp.com/ about.html (accessed 7 January 2016).

Hobsbawm, E. 1996. The Age of Revolution 1789-1848. New York: Vintage Books.

Indiana University of Pennsylvania. n.d. 'Deborah Henson-Conant'. Online at https://www. iup.edu/livelyarts/past-seasons/2014-2015/music/deborah-henson-conant/ (accessed 15 November 2018).

Ivers, Eileen. n.d. Eileen Ivers-About. Online at http://www.eileenivers.com/about/ (accessed 7 January 2016).

Jimi Hendrix of Spoons, The. n.d. Facebook page. Online at https://www.facebook.com/ jimihendrixofspoons/ (accessed 12 February 2018).

Joburg. 2008. 'West Africa Meets Jimi Hendrix'. Online at https://tinyurl.com/y9bjch6h (accessed 7 January 2016).

JPlay. n.d. 'Bela Fleck'. Online at http://www.jplay.com.au/JSite/ViewArtist.aspx?ArtistlD= 2414 (accessed 7 January 2016).

Kassabian, Anahid. 2010. 'Have Canons Outlived their Usefulness?' Journal of Popular Music Studies 22/1: 74-78. https://doi.org/10.1111/j.1533-1598.2010.01222.x

\section{equinoxonline}


Kefner, Kurt. n.d. 'All Music Review-Lui Pui-Yuen'. Online at https://www.allmusic.com/ album/china-music-of-the-pipa-mw0000674776 (accessed 7 January 2016).

Keogh, Brent. 2015. 'The Wizard of Oud: A Case Study of Sydney Based Oud Player Joseph Tawadros'. Journal of Music Research Online 6: 1-12.

Levine, Donald N. 1984. 'The Liberal Arts and the Martial Arts'. Association of American Colleges, Liberal Education 70/3: 235-51.

Maan, R. 2012. 'Mali's Bassekou Kouyate is the Jimi Hendrix of the ngoni'. Online at http:// music.cbc.ca/\#/blogs/2012/3/Malis-Bassekou-Kouyate-is-the-Jimi-Hendrix-ofthe-ngoni (accessed 7 January 2016).

McClain, Jordan M. 2016. 'Framing in Music Journalism: Making Sense of Phish's "LeftField" Success Story'. Journal of Popular Culture 49/6:1206-1223. https://doi.org/10. 1111/jpcu. 12489

Moi, Toril. 1998. Sexual/Textual Politics. London: Routledge.

NiftyNYC. 2012. 'Thursday, July 19th: Dawoud-"the Jimi Hendrix of the Sitar"'. Online at http://www.niftynyc.com/2012/07/19/thursday-july-19th-dawoud-th e-jimi-hendrix-of-the-sitar/ (accessed 7 January 2016).

Perchard, Tom. 2011. 'Thelonious Monk Meets the French Critics: Art and Entertainment, Improvisation, and its Simulacrum'. Jazz Perspectives 5/1: 61-94. https://doi.org/10. 1080/17494060.2011.590681

Phillips, W. n.d. 'Ivo Papasov and his Wedding Band'. Online at https://www.womex.com/ virtual/messechina_music/ivo_papasov_and_his (accessed 7 February 2018).

Queenslander. 1920. Saturday, 7 August: 15.

Said, Edward. 1978. Orientalism. New York: Vintage.

Scannell, J. 2011. 'Working to Design: The Self-Perpetuating ldeology of Rock or ... "The New Bob Dylan"'. PORTAL Journal of Multidisciplinary International Studies 8/1:1-15. https://doi.org/10.5130/portal.v8i1.1716

Schmutz, V., and A. Faupel. 2010. 'Gender and Cultural Consecration in Popular Music'. Social Forces 89/2: 685-707. https://doi.org/10.1353/sof.2010.0098

Strong, C. 2011. 'Grunge, Riot Grrrl, and the Forgetting of Women in Popular Culture'. Journal of Popular Culture 44/2: 398-416. https://doi.org/10.1111/j.1540-5931.20 11.00839.x

This is Africa. 2011. 'The Jimi Hendrix of the Desert'. Online at https://tinyurl.com/ybeq36xv (accessed 7 January 2016).

Uhlmann, Mark. 1988. The Canberra Times, 10 November: 24.

von Appen, R., and A. Doehring. 2006. 'Nevermind the Beatles, here's Exile 61 and Nico: "The top 100 records of all time"-a canon of pop and rock albums from a sociological and an aesthetic perspective'. Popular Music 25/1: 21-39. https://doi.org/10.1017/S02 61143005000693

Vallikanth, C. S. 2006. 'Prasanna: Electric Ganesha Land'. Online at http://www.allaboutjazz.com/prasanna-electric-ganesha-land-by-csvallikanth.php (accessed 7 January 2016).

Whitmore, L. B., and A. Blumenthal. 2011. 'Exposed: 10 Female Guitarists You Should Know'. Guitar World, 9 February (online 7 January 2016).

Wolf, S. 2014. 'Meet the "Jimi Hendrix of the Bagpipe"'. Online at http://www.cpr.org/ news/story/meet-jimi-hendrix-bagpipe (accessed 7 January 2016).

World Music Central. 2009. 'Speed Caravan's Debut Album Kalashnik Love out on 28 September 2009'. Online at https://tinyurl.com/yd46ydf7 (accessed 7 January 2016).

\section{eevuinoxonline}

